\title{
THE RESPONSE OF URINARY 17-HYDROXY- CORTICOIDS TO CORTICOTROPHIN ZINC AS A TEST OF ADRENAL CORTICAL FUNCTION
}

\author{
BY \\ J. S. JENKINS \\ From the Department of Pathology, St. Bartholomew's Hospital, London*
}

(RECEIVED FOR PUBLICATION APRIL 8, 1957)

An increased interest in the study of the adrenal cortex, together with the ready availability of corticotrophin (A.C.T.H.), have, in recent years, led to the development of improved methods for the assessment of adrenal cortical function. The first of such methods was devised by Thorn, Forsham, Prunty, and Hills (1948) and depended upon the fall in blood eosinopkils after iniection of a single dose of corticotrophin. It was subsequently realized, however, that this test was by no means specific, since a fall in eosinophils could be produced by the injection of adrenaline, for example, without any effect on the adrenal steroids (Nelson, Sandberg, Palmer, and Glenn, 1952). Moreover, there is a considerable spontaneous variation in the eosinophil count and results may be difficult to interpret when the initial count is low.

The urinary 17 -ketosteroid excretion after corticotıophin provides a more valuable indication of adrenal cortical function and many of the current tests rely on this estimation. In males, however, the 17-ketosteroids are only partly derived from the adrenal cortex, and sometimes a clearly defined rise after corticotrophin is not obtained even in normal individuals. Jenkins, Forsham, Laidlaw, Reddy, and Thorn (1955) find that $14 \%$ of normal controls showed a rise of less than $2 \mathrm{mg}$. in 24 hours.

Recently, relatively simple methods have been devised for the estimation of urinary 17-hydroxycorticoids, and it seems that these methods provide a more direct measure of adrenal cortical function since the 17-hydroxycorticoids represent that fraction of the adrenal steroids known as the glucocorticoids, of which hydrocortisone and its urinary metabolites are the most important. It is now recognized that for an adequate assessment of its function a prolonged stimulation of the adrenal cortex is necessary. Jenkins et al. (1955) describe

*Permanent address: St. George's Hospital, London. the use of an eight-hour intravenous infusion of corticotrophin, but this is inconvenient, and occasional anaphylactic reactions have been reported. The same authors find that corticotrophin gel injected intramuscularly is equally effective in producing a rise in 17-hydroxycorticoids. Recently, a very effective aqueous suspension of corticotrophin and zinc phosphate has been introduced, which is more easily injected than the gel preparation. Greene and Vaughan-Morgan (1954), den Oudsten, van Leeuwen, and Coers (1954), and Ferriman, Anderson, and Turner (1954) have shown that corticotrophin-zinc phosphate has a prolonged and powerful stimulatory effect on the adrenal cortex, as reflected by the eosinophil count and 17 ketosteroid excretion. The purpose of the present report is to describe a test of adrenal cortical function based upon the estimation of urinary 17 hydroxycorticoids before and after the administration of corticotrophin zinc.

\section{Methods}

Twenty-four-hour urine collections were started at 9 a.m. The first day was used as a control, and on the second day $40^{\circ}$ units of corticotrophin zinc was injected intramuscularly at 9 a.m. and 9 p.m. In most cases urine collection was continued for the third day.

Urinary 17-hydroxycorticoids were estimated by the method of Reddy, Jenkins, and Thorn (1952) as mod:fied by Reddy (1954) and involved the extraction of urine with butanol followed by the colour reaction of Porter and Silber (1950). This method has the merit of being relatively simple to perform and rapid enough for estimations to be completed within a few hours. Two alterations have been made in the procedure described by Reddy (1954). The first employs the suggestion of Smith, Mellinger, and Patti (1954), who found that the use of $56 \%$ instead of $62 \%$ sulphuric acid, allowing a longer incubation time, reduced blank values and increased colour development. The second modification involves a simplified method 
for the purification of the commercial butanol. One litre of butanol ("analar") was acidified to $p H$ with $50 \%$ sulphuric acid. One hundred milligrams of recrystallized phenylhydrazine was then added and the mixture heated to $60^{\circ} \mathrm{C}$. for 30 minutes. At the end of this time the temperature was raised to boiling point and the butanol distilled at $117^{\circ} \mathrm{C}$., discarding the first $50 \mathrm{ml}$. Urinary 17-hydroxycorticoids estimated by this method, using cortisone as a standard, showed in 50 individuals a normal range of 3 to $10.2 \mathrm{mg}$. per 24 hours (mean $6.3 \mathrm{mg}$.).

Urinary 17-ketosteroids were estimated by the standard method proposed by the Medical Research Council Committee on Clinical Endocrinology (1951).

\section{Results}

Normal Response to Corticotrophin. - The administration of corticotrophin zinc to 24 patients with no clinical evidence of adrenal cortical disease resulted in an unequivocal rise in urinary 17hydroxycorticoids in every case, although there

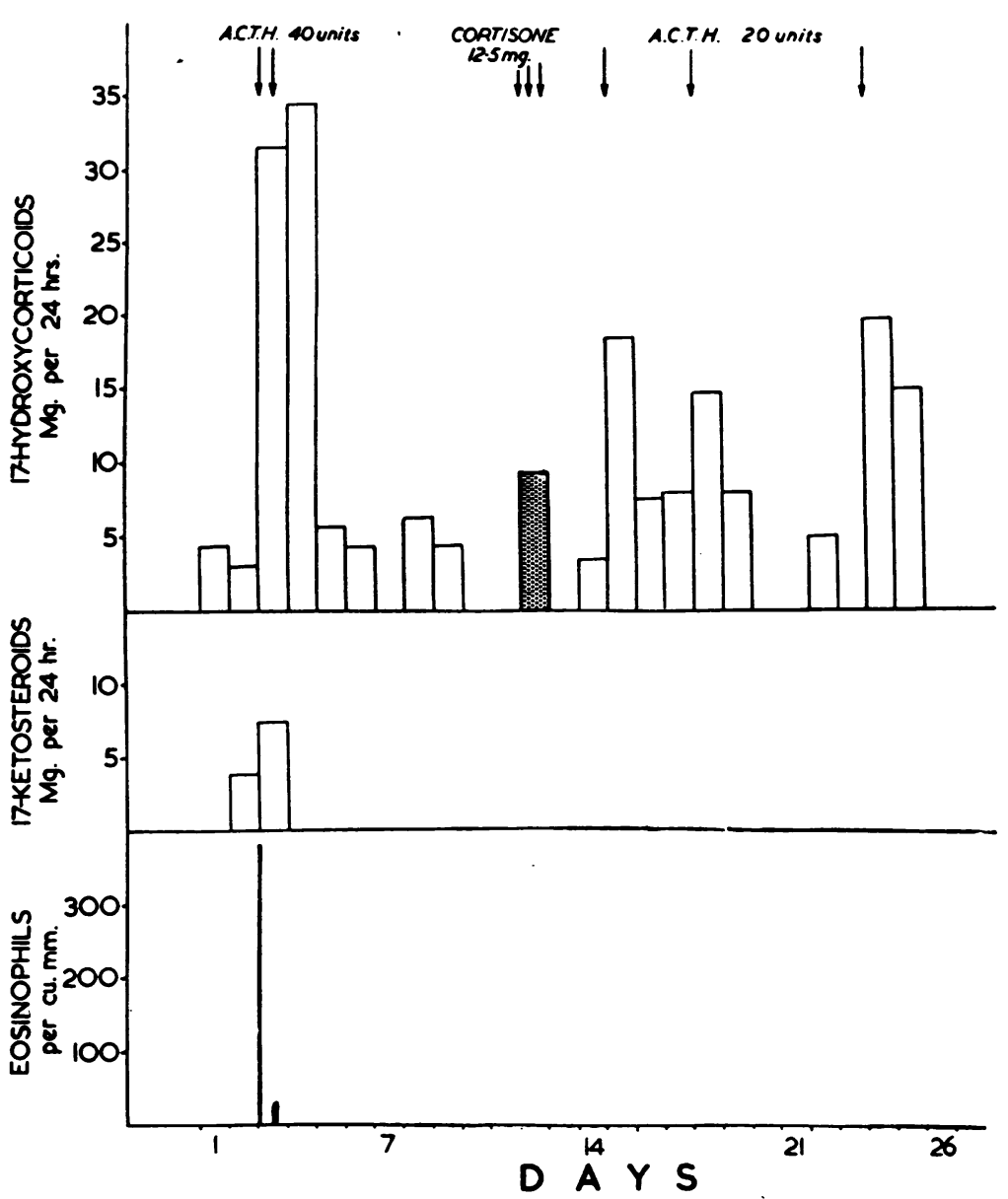

FIG. 1.-Response of normal woman, aged 59, to corticotrophin zinc were considerable differences both in the speed and magnitude of the response. The initial control values ranged from $3 \mathrm{mg}$. to $9.3 \mathrm{mg}$., and the increase ranged from $6.6 \mathrm{mg}$. to $27.6 \mathrm{mg}$. (mean $16.1 \mathrm{mg}$.) during the day of corticotrophin and from $19.4 \mathrm{mg}$. to $59 \mathrm{mg}$. (mean $36.6 \mathrm{mg}$.) during the following day. One other normal female was not included in this series because she had been receiving small doses of corticotrophin twice weekly for several months, elsewhere, on a mistaken diagnosis of hypopituitarism. Her initial level was $8.1 \mathrm{mg}$. and after the corticotrophin test there was an enormous increase of $35.4 \mathrm{mg}$. and $90.9 \mathrm{mg}$. on the successive days. This result agrees with the finding of Forsham, di Raimondo, Island, Rinfret, and Orr (1955) that repeated small amounts of corticotrophin increase the sensitivity of the adrenal to subsequent stimulation by larger doses.

In Fig. 1 the responses of the eosinophils, the 17-ketosteroids, and the 17-hydroxycorticoids have been compared in a normal person. It will be seen that in this particular case a definite fall in eosinophils was obtained, but the rise in the 17-ketosteroid level was much less impressive than the rise in 17-hydroxycorticoids. Fig. 1 shows that even smaller doses of corticotrophin zinc cause a rise in 17-hydroxycorticoids lasting from 24 to 48 hours. The effect of oral cortisone, $12.5 \mathrm{mg}$. three times daily, is included for comparison.

Addison's Disease. - The Table and Fig. 2 show the results obtained when the test is carried out on patients suffering from Addison's disease. Three cases were studied, of which one patient, J.H., was untreated at the time of investigation. This patient showed most of the clinical features of Addison's disease, and the 17-hydroxycorticoid excretion was 2.4 mg. The administration of corticotrophin caused no rise in either the 17-hydroxycorti- 


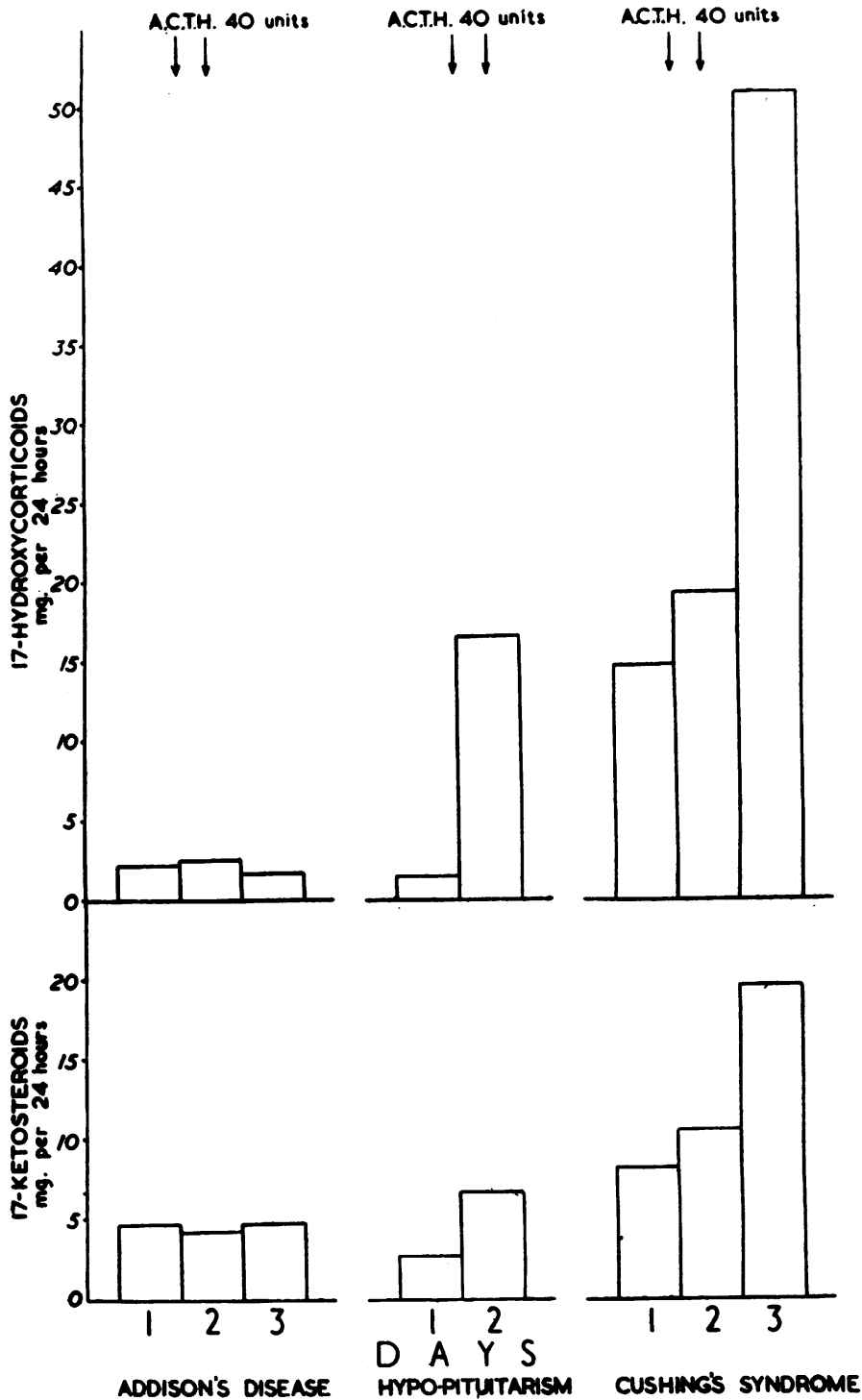

Fig. 2.-Response of man, aged 21, with untreated Addison's disease; man, aged 63, with hypopituitarism; and a woman, aged 26, with Cushing's syndrome. insufficiency secondary to hypopituitarism is shown in Fig. 2 and the Table. A male patient aged 0 63 suffering from hypopituitarism showed the low 17-hydroxycorti- $\frac{\bar{\sigma}}{\frac{}{7}}$ coid excretion of $1.5 \mathrm{mg}$., but this $\stackrel{\mathbb{Q}}{\varrho}$ level rose to $16.5 \mathrm{mg}$. following corticotrophin. In contrast, the $\vec{\circ}$ 17-ketostereids rose only from $2.7-$ $\mathrm{mg}$. to $6.6 \mathrm{mg}$. A second male $\vec{\omega}$ patient also showed a good re- $\frac{\rho}{0}$ sponse, the increase in 17-hydroxy-? corticoids being $9.9 \mathrm{mg}$. on the day $\overrightarrow{.}$ of corticotrophin and $12 \mathrm{mg}$. on the $\overrightarrow{-}$ following day, although the corre- $\infty$ sponding rise in 17-ketosteroids was $\frac{\text { ? }}{2}$ only $1 \mathrm{mg}$. and $1.4 \mathrm{mg}$. on these $\vec{c}$ two days. A female patient with long-standing hypopituitarism fol- $\frac{2}{2}$ lowing post-partum necrosis of the anterior pituitary showed a more $\vec{\theta}$ sluggish reaction, no rise occurring $\stackrel{\circ}{\infty}$ on the day of corticotrophin, but a rise of $5.6 \mathrm{mg}$. was obtained on the following day. While an unequivocal increase in 17-hydroxycorticoids was obtained in all three $\underset{\perp}{\perp}$ patients using the standard test, the $\overrightarrow{\vec{F}}$ delayed response occurring in the $\frac{0}{3}$ third patient indicates that in cases of suspected hypopituitarism it would be wise to prolong the administration of corticotrophin for three days in order to ensure 3 adequate stimulation.

Cushing's Syndrome.-The application of the test to two patients suffering from Cushing's syndrome $\frac{}{0}$ due to bilateral adrenal cortical hyperplasia is also shown in Fig. $2 \mathrm{~N}$ and the Table. In these cases the

corticoid or 17-ketosteroid levels. The remaining two patients had suffered from Addison's disease for several years and were receiving treatment with oral cortisone, $12.5 \mathrm{mg}$. twice daily. This dose was sufficient to produce normal 17hydroxycorticoid excretion under ordinary conditions, but after corticotrophin there was no significant alteration.

Hypopituitarism.-The use of the 17-hydroxycorticoid test in differentiating between the primary adrenal failure of Addison's disease and adrenal control 17-hydroxycorticoid values were higherN than normal, and after corticotrophin a consider- $\omega$ able response was obtained, indicating that the already hyperplastic adrenal cortex was capable? of being further stimulated by exogenous corticotrophin.

\section{Discussion}

The results shown above indicate that th@ response of urinary 17-hydroxycorticoids after the administration of corticotrophin zinc differentiates between individuals with normal adrenal corticab 
TABLE

EFFECT OF CORTICOTROPHIN ZINC ON URINARY 17-HYDROXYCORTICOIDS IN ABNORMALITIES OF ADRENAL CORTEX

\begin{tabular}{|c|c|c|c|c|c|c|}
\hline \multirow[b]{2}{*}{ Case } & \multirow[b]{2}{*}{ Age } & \multirow[b]{2}{*}{ Sex } & \multirow[b]{2}{*}{ Diagnosis } & \multicolumn{3}{|c|}{ 17-Hydroxycorticoids } \\
\hline & & & & $\begin{array}{c}\text { 1st Day } \\
\text { (Control) } \\
\text { (mg.'24 hr.) }\end{array}$ & \begin{tabular}{|c|} 
2nd Day \\
(A.C.T.H.) \\
(mg. \\
Change \\
per $24 \mathrm{hr})$.
\end{tabular} & $\begin{array}{c}\text { 3rd Day } \\
\text { (mg. } \\
\text { Change } \\
\text { per } \\
24 \mathrm{hr} . \text { ) }\end{array}$ \\
\hline J.H. & 21 & M & $\begin{array}{l}\text { Addison's } \\
\text { disease }\end{array}$ & $2 \cdot 4$ & $+0 \cdot 2$ & -0.8 \\
\hline V.w. & 18 & M & $\begin{array}{l}\text { Addison's } \\
\text { disease } \\
\text { (treated) }\end{array}$ & $6 \cdot 0$ & +1.9 & \\
\hline $\begin{array}{l}\text { I.P. } \\
\text { W.P. }\end{array}$ & $\begin{array}{l}46 \\
63\end{array}$ & $\begin{array}{l}\mathbf{F} \\
\mathbf{M}\end{array}$ & $\begin{array}{c}\text { Hypo- } \\
\text { pitui- } \\
\text { tarism }\end{array}$ & 3.6 & $+1 \cdot 3$ & \\
\hline $\begin{array}{l}\text { S.W. } \\
\text { J.B. } \\
\text { C.L. }\end{array}$ & $\begin{array}{l}59 \\
40 \\
26\end{array}$ & $\begin{array}{l}\mathbf{M} \\
\mathbf{F} \\
\mathbf{F}\end{array}$ & Cushing's & $\begin{array}{l}2 \cdot 4 \\
2 \cdot 0\end{array}$ & $\begin{array}{r}-17.0 \\
+9.9 \\
-0.1\end{array}$ & $\begin{array}{r}+12.0 \\
+5.6\end{array}$ \\
\hline P.S. & 26 & $\mathbf{F}$ & $\begin{array}{c}\text { syndrome } \\
\text {," }\end{array}$ & $\begin{array}{l}14 \cdot 3 \\
20 \cdot 1\end{array}$ & $\begin{array}{r}+50 \\
+8.7\end{array}$ & $\begin{array}{l}+36 \cdot 4 \\
+18 \cdot 3\end{array}$ \\
\hline
\end{tabular}

function and those suffering from various abnormalities of the adrenal cortex. The lack of response in Addison's disease is contrasted with the increase obtained in hypopituitarism although this may be delayed in some patients. In the cases of Cushing's syndrome which were investigated, the increase in 17-hydroxycorticoids after the giving of corticotrophin suggested that the patients were suffering from adrenal cortical hyperplasia rather than a malignant tumour, although laparotomy was necessary for confirmation of the diagnosis. Jenkins et al. (1955) have obtained similar results, using intravenous infusion of corticotrophin or intramuscular corticotrophin gel. These authors conclude that a rise in urinary 17-hydroxycorticoids of greater than $5 \mathrm{mg}$. per 24 hours is the best index of normal adrenal cortical response.

The injection of 40 units of corticotrophin zinc 12-hourly provides, in a convenient form, the sustained intensive stimulus required for adequate adrenal function tests and it appears that this preparation has a more prolonged action than corticotrophin gel when it is given in equivalent doses to the same patient (personal finding). Moreover, no anomalous results due to resistance to intramuscular corticotrophin necessitating intravenous infusion have so far been encountered with the zinc preparation.

Nabarro (1954), using corticotrophin gel, has suggested that there is a place for the eosinophil count and the urinary sodium/potassium ratio as screening tests before carrying out the more timeconsuming urinary 17-ketosteroid estimation. The limitations of the eosinophil count have already been mentioned and the urinary sodium/potassium ratio may be affected by variations in the diet unless this is rigidly controlled. With the development of a method for the estimation of urinary 17-hydroxycorticoids which is more rapid than the 17-ketosteroid estimation and which provides a more sensitive index of adrenal cortical response, there appears to be less need for the indirect tests.

\section{Summary}

An increase in urinary 17-hydroxycorticoids is a sensitive index of adrenal cortical response to corticotrophin.

Patients with Addison's disease show no increase in 17-hydroxycorticoids whereas in hypopituitarism there is a definite response.

In Cushing's syndrome due to adrenal cortical hyperplasia there is a good response to corticotrophin.

Corticotrophin zinc provides a sustained, intensive stimulation of the adrenal cortex in a convenient form.

I would like to thank Dr. A. W. Spence and Dr. N. C. Oswald for permission to investigate patients under their care. I am indebted to Dr. A. B. Anderson and Mrs. A. M. Robinson, D.Sc., of the Department of Pathology, St. Bartholomew's Hospital, for providing the facilities for carrying out this work and for much helpful advice. Estimations of 17-ketosteroids were carried out by Miss A. Dimoline.

\section{REFERENCES}

Ferriman, D. G., Anderson, A. B., and Turner, P. P. (1954). Lancet, 1,545 .

Forsham, P. H., Raimondo, V. di, İsland, D., Rinfret, A. P.. and Orr, R. H. (1955). Ciba Foundation Colloquia on Endocrinology, 8, 279.

Greene, R., and Vaughan-Morgan, J. (1954). Lancet, 1, 543.

Jenkins, D., Forsham, P. H., Laidlaw, J. C., Reddy, W. J., and Thorn, G. W. (1955). Amer. J. Med., 18, 3.

Medical Research Council Committee on Clinical Endocrinology (1951). Lancet, 2, 585 .

Nabarro, J. D. N. (1954). Ibid., 2, 1101.

Nelson, D. H., Sandberg, A. A., Palmer, J. G., and Glenn, E. M. (1952). J. clin. Endocr., 12, 936.

Oudsten, S. A. den, Leeuwen, L. van, and Coers, R. J. (1954). Lancet, 1, 547.

Porter, C. C., and Silber, R. H. (1950). J. biol. Chem., 185, 201.

Reddy, W. J. (1954). Metabolism, 3. 489.

Jenkins, D., and Thorn, G. W. (1952). Ibid., 1, 511

Smith, R. W., Mellinger, R. C., and Patti, A. A. (1954). J. clin. Endocr., 14, 336.

Thorn, G. W.. Forsham, P. H., Prunty, F. T. G., and Hills, A. G. (1948). J. Amer. med. Ass., 137, 1005. 